\title{
RAYMOND CARVER E SEUS LOSERS: UMA BREVE HISTÓRIA DOS FRACASSADOS NA AMÉRICA
}

\author{
Carlos Böes de Oliveira ${ }^{1}$
}

\begin{abstract}
RESUMO: Este artigo pretende traçar o caminho dos Losers na história moderna e pós-moderna da América do Norte, elaborando sobre o poder do imaginário fundador da nação como elemento fundamental para o nascimento destes fracassados. Além disso, será analisada a construção dos losers na literatura de Raymond Carver, onde a grande maioria de seus personagens se identifica com esse grupo descentrado da nação americana. Através de um encontro interdisciplinar entre História e Literatura será proposta uma leitura de como os ideais de sucesso que pertencem ao imaginário da América, inevitavelmente, dão espaço para o nascimento dos Losers. Para trabalhar a questão da história, será utilizado os conceitos de micro-história e Nova História, e para trabalhar com os personagens de Carver, o conceito de Linda Hutcheon sobre os descentrados da pós-modernidade será utilizado.
\end{abstract}

Palavras-chave: Raymond Carver. Losers. História. Nova História. América.

\section{Introdução}

Scott A. Sandage salienta que "o fracasso não é o lado negro do sonho americano, mas sua própria fundação. O sonho americano dá a cada um de nós a oportunidade de ser um loser por natureza". (2005, p.278) A ideologia da América, como uma ideologia capitalista com teores liberais, cria uma disparidade necessária entre classes sociais. As classes subjugadas, como é sabido, são inexoravelmente vitais a estrutura capitalista. É através dessas classes que as ideologias das classes dominantes exercem maior influência. E é através dos homens (e mulheres) bem sucedidos que a mesma ideologia se mantém e se afirma.

Os losers habitam a sombra superdimencionada da ambição. Por muitas décadas os Americanos foram iludidos a acreditarem que o quanto mais duro você se empenhasse no trabalho, o quanto mais ambicioso a pessoa era, maiores

\footnotetext{
${ }^{1}$ Doutorando em processos e manifestações culturais pela Feevale; mestre em literaturas de língua inglesa pela UFRGS; Graduado em letras com habilitação em inglês e literaturas de língua inglesa pela ULBR. E-mail: caio.boes@gmail.com

${ }^{2}$ Failure is not the dark side of the American Dream; it is the foundation of it. The American Dream gives each of us the chance to be a born loser.
}

Revista de Letras JUÇARA, Caxias - Maranhão, v. 01, n. 01, p. 05 - 23, Jul. 2017. 
seriam as chances de alcançar o sucesso. E o sonho na América, é que ninguém é um loser por natureza. Ou, como o próprio Raymond Carver escreveu em seu ensaio intitulado Fires:

\begin{abstract}
Por anos, minha esposa e eu tínhamos uma crença de que se trabalhássemos duro, e tentássemos fazer a coisa certa, as coisas certas aconteceriam conosco. Realmente não é uma coisa feia de se acreditar. Trabalho duro, metas, boas intenções, lealdade, nós acreditávamos que eram virtudes e que algum dia seríamos recompensados. Nós sonhávamos quando nós tínhamos tempo para sonhar. Mas percebemos que trabalho duro e sonhos não são o suficiente $^{3}$. (1983, p.33)
\end{abstract}

Pode-se ousar dizer que realizações humildes são um golpe menos dolorido para os Americanos do que uma ambição humilde. Já que, uma ambição diminuta revela a fraqueza sobre o caráter de um homem. "Um Americano que não tenha perspectiva ou planos, sem nenhuma ânsia, praticamente deixa de existir", diz Sandage. (2005, p.20)

Aonde é possível encontrar a história do fracasso na América? Onde se encontra o lado pessimista dessa narrativa otimista que é a América? Nos meados de 1850, Abraham Lincoln disse que "homens são sedentos em publicarem suas conquistas, mas, no mínimo, tímidos em publicarem seus fracassos" $5 "$. (apud SANDAGE, 2005, p.8)

$\mathrm{O}$ conceito de loser tem mudado constantemente em nossa cultura. Ou melhor, o conceito tem sempre se alargado semanticamente. Inicialmente, envolvia aqueles que não se ajustavam a ideologia capitalista. Aqueles que não conseguiam se adaptar, e que eram ejetados do sistema e de sua busca indomável pelo sucesso. Aqueles losers carregavam muitos nomes, eram chamados de falidos, bons-pra-nada, terceira categoria, ninguém, pequeninos, vadios, fritas pequenas, já-foram, tinham-sido. Mas estes nomes vêm de uma época onde apenas homens brancos podiam ser vistos como losers. Apenas

\footnotetext{
${ }^{3}$ For years my wife and I had held to a belief that if we worked hard and tried to do the right things, the right things would happen. It's not such a bad thing to try and build a life on. Hard work, goals, good intentions, loyalty, we believed these were virtues and would someday be rewarded. We dreamed when we had the time for it. But, eventually, we realized that hard work and dreams were not enough.

${ }^{4}$ An American with no prospects or plans, with nothing to look forward to, almost ceases to exist.

${ }^{5}$ Men are greedy to publish the success of [their] efforts, but meanly shy as to publishing the failures of men. Men are ruined by this one sided practice of concealment of blunders and failures
}

Revista de Letras JUÇARA, Caxias - Maranhão, v. 01, n. 01, p. 05 - 23, Jul. 2017. 
homens brancos que falhavam nos negócios, que tinham seus nomes tingidos, podiam calçar os sapatos ideológicos do loser.

Quem é o loser hoje? O alcance semântico do pós-modernismo consegue absorver diferentes tipos de pessoas. Todas as minorias pertencentes à América podem ser inseridas na categoria dos losers $\mathrm{Na}$ metade do século $\mathrm{XX}$, as mulheres, os negros, os homossexuais, os latinos, os estrangeiros, os nativoamericanos, os nerds, os sulistas, etc,. É necessário se perguntar: em que momento o loser se tornou uma questão de identidade e não uma questão de cunho financeiro? Porque os Americanos conectam-se a metáforas capitalistas, ou tratam a identidade como uma analogia da forma com que se trata um negócio? Porque mensuram seus fracassos com os dólares perdidos tanto quanto o fazem com os sonhos perdidos?

\section{A nova história}

Na metade do século $X X$ muitos questionamentos foram levantados sobre questões que ancoravam a filosofia modernista. A relação com a "verdade", a unidade, a universalidade, o centro, e a cientificidade foram conceitos colocados em cheque. $\mathrm{O}$ que os pensadores, ditos pós-modernos entendem é que não há mais espaço para respostas definitivas e que tudo não passa de uma representação, uma retórica de verdade. A disciplina da História não ficou distante de ser questionada pela sua "cientificidade". Hayden White salienta que

[...] de Valéry e Heidegger a Sartre, Lévi-Strauss e Michel Foucault expressaram sérias dúvidas sobre 0 valor de uma consciência especificamente "histórica", sublinharam o caráter fictício das reconstruções históricas e contestaram as pretenções da história a um lugar entre as ciências. (1995, p.17)

Percebeu-se que o historiador não fala de um lugar imparcial. Ele mesmo, como enunciador, carrega elementos ideológicos incapazes de serem "apagados". Cardoso salienta que a história como disciplina, costumava

[...] afirmar que os pretensos centros (entenda-se: lugares de onde se fala) a partir dos quais se afirmariam as diversas posturas diante da 
mesma não são legítimos ou naturais, mas sim ficções arbitrárias e passageiras, articuladors de interesses que não são universais: são sempre particulares, relativos a grupos restritos e socialmente hierarquizados de poder (em outras palavras: não há História; há histórias"de" e "para" os grupos em questão) (2011, p.15)

Desta perspectiva, nota-se que a neutralidade do historiador para analisar os fatos, ou até mesmo selecionar sua corpora de pesquisa não sai ilesa do universo ideológico e parcial.

\begin{abstract}
As dimensões ideológicas de um relato histórico refletem o elemento ético envolvido na assunção pelo historiador de uma postura pessoal sobra a questão da natureza do conhecimento histórico e as implicações que podem ser inferidas dos acontecimentos passados para 0 entendimento dos atuais. (WHITE, 1995, p.36)
\end{abstract}

Pensando estes questionamentos, chega-se a conclusão de que em culturas diferentes, a historicidade também é diferente. O ponto de vista se torna um preceito comum nos estudos da história hoje. A Nova História, a história vinda de baixo, ou seja, aquela contada pelos sujeitos que não haviam tido voz anteriormente para contar a sua própria história, ou a história vista por um determinado prisma, começa a aparecer. A Nova História é "[...] preocupada centralmente com a diversidade dos objetos e a alteridade cultural, entre sociedades e dentro de cada uma delas." (CARDOSO, 2011, p.3) Nesta condição, temos a história da loucura (Foucault), A história pós-colonial, a história das mulheres, dos negros, dos homosexuais, e a história dos losers na América, como propomos apresentar.

Outro elemento da Nova História é aonde ela vai buscar suas fontes, já que documentos oficiais, ou registros comerciais, entre outros exemplos, também representavam uma centralidade do pensamento. Elas vinham carregadas de elementos ideológicos. Por falta de documentos "tradicionais" para escrever a história da diversidade, busca-se outras alternativas, e diferentes tipos de "provas". Para traçar a história do loser, Sandage (2005) baseia-se em cartas de suícidio, cartas pessoais, declarações de falência e também na literatura.

A seguir, será apresentado uma breve história do loser na América, seguindo com a condição do loser no mundo pós-moderno, e, finalmente, será apresentado as representações de loser na literatura de Raymond Carver. 


\section{A história do loser na América}

Nos séculos XVII e XVIII, os Americanos construíram uma ideologia que focava no empenho do indivíduo. O individualismo, junto com o conceito da liberdade, sempre foi integrante na coluna dorsal do pensamento norteamericano. A maneira que os Americanos olham para estes conceitos hoje é completamente diferente do que o fizeram quando estes elementos fundadores nasceram. A herança Calvinista ensinou aos Americanos que a luta individual era necessária. Max Weber acentuou, em seu trabalho clássico de 1905, A Ética Protestante e o Espírito do Capitalismo, que apontar para o sucesso é uma virtude obrigatória, até mesmo um dever, na cultura norte-americana.

Os indivíduos Americanos dos séculos XVII e XVIII que seguiam uma doutrina Calvinista idolatravam a liberdade, e o individualismo era visto como uma forma legítima para atingir este objetivo. Não importa o quão metafísico o termo liberdade possa parecer, os americanos viam esse conceito como algo tangível (e, talvez, ainda o vejam), e guiaram suas vidas com esse preceito, como rota de destino. Mas, quando o capitalismo alargou seus braços, quando a guerra civil norte-americana se tornou iminente, a situação mudou. Esta situação fez com que a ideologia capitalista ultrapassasse suas fronteiras de mercado, infiltrando-se em ideologias sociais, governamentais e individuais. A busca pelo lucro, o acúmulo sem fim de capital, a crença de que o trabalho sem cessar é um dogma, são elementos que guiam essa ideologia. Guiados pelos mesmos princípios do individualismo, do trabalho duro, e da busca pela liberdade, os americanos redirecionaram o seu ímpeto e identidade nacional. Não é mais a liberdade que os leva ao sucesso, mas sim, a ambição e a cobiça. "Com poucas exceções, a única identidade vista como legítima na America é uma identidade capitalista; em cada passo da vida, investimentos e aquisições são a chave para seguir adiante e evitar a estagnação6". (SANDAGE, 2005, p. 4) A revolução industrial ocorrida no final do século XIX e início do século XX remodelou a ética norte-americana. Para uma grande parte dos americanos, a ambição tornou-se o ímpeto e o mote da

${ }^{6}$-With few exceptions, the only identity deemed legitimate in America is a capitalist identity; in every walk of life, investment and acquisition are the keys to moving forward and avoiding stagnation

Revista de Letras JUÇARA, Caxias - Maranhão, v. 01, n. 01, p. 05 - 23, Jul. 2017. 
nação. O crescimento econômico do país magnificou o desejo latente do povo em crescer também. "A ambição tornou-se mais legítima ao mesmo tempo em que a mobilidade ocupacional destituiu a vocação Calvinista; o pecado do orgulho deu lugar à virtude do esforço7" (SANDAGE, 2005, p.14).

\section{Caindo na hora de erguer-se}

O self-made man do século XIX caminhava de mãos dadas com sua carametade, o loser. A cultura imperialista foi capaz de "apagar" a história daqueles que falharam. A América do século XIX é vista como um período exemplar de fortuna e empreendimento. A história silenciada do fracasso, as vozes dos homens, mulheres e famílias que falharam na busca do sucesso reverbera em diários, cartas suicidas, cartas pessoais, relatórios econômicos, biografias, casos de falência e na literatura. As histórias sobre o fracasso estão em todo lugar. Scott A. Sandage, professor associado de História na universidade Carnegie Mellon será o nosso guia para analisar a figura do loser e sua história na América. Em seu livro Born Losers: A History of failure in America (2005), Sandage examina a influência e a história dessas figuras. Ele declara que o loser é o bicho-papão da nação, e sua história nos últimos dois séculos revela o lado negro do sucesso e como o esforço por crescimento econômico remodelou o ser e a alma do país. Sandage inicia seu trabalho mapeando o fracasso desde a época colonial até a tragédia de Columbine, explorando como o fracasso evoluiu de uma perda nos negócios à um déficit de personalidade, de um percalço na carreira à uma sensação de auto-valorização pelos americanos.

No imaginário popular americano se diz que com um pouco mais de esforço, com um pouco mais de determinação, o que estava condenado ao fracasso iminente, pode se tornar um sucesso total, e que o fracasso recai em deixar de tentar. Por outro lado, "a era do self-made man também era a época dos homens falidos"." (SANDAGE, 2005, p. 17) A história conta os contos daqueles que foram bem-sucedidos no universo dos empreendimentos capitalistas. Mas

\footnotetext{
$7 \|$ Ambition grew more legitimate as occupational mobility deposed the Calvinist sense of calling; the sin of pride made room for the virtue of striving

${ }^{8}$ The age of the self-made man was also the age of the broken man.
}

Revista de Letras JUÇARA, Caxias - Maranhão, v. 01, n. 01, p. 05 - 23, Jul. 2017. 
estes vencedores representam um número diminuto comparado aos numerosos fracassos que viviam vidas em desespero mudo.

O que acontece a América quando aqueles que caem são pessoas trabalhadoras, que se esforçam e dão o seu melhor? Quem deve ser culpado? A crença e o imaginário sobre este trabalhador que se dedica e alcança o sucesso persiste até nossos dias. A cultura de massa é a grande disseminadora dessa filosofia. Filmes e programas televisivos usam, em larga escala, a imagem do loser que, depois de trabalhar duro, falhando, e trabalhando duro novamente, finalmente alcança o sucesso. A mídia ainda vende a imagem da América como a terra da oportunidade. As justificativas para o fracasso hoje são as mesmas usadas há dois séculos atrás, como Sandage aponta:

Provérbios Franklinescos colocam o fracasso na culpa da preguiça, embriaguez, ganância, ignorância, extravagância e um monte de outros pecados. Mas o que fazer quando o mercado ejeta um homem honesto e trabalhador?[...] As vicissitudes do capitalismo são tantas que negócios honestos e trabalho duro podem levar ao fracasso ${ }^{9}$ (2005, p.15).

Os americanos que estavam fracassando não eram aqueles que não tinham ambição ou habilidade. Eram os negócios que acabavam eliminando seus próprios negócios, ou seja, a economia nacional e suas características mutáveis é que estava levando os americanos esforçados e trabalhadores para o fundo da existência social. Muitos produtores e homens de negócio não estavam preparados para dirigirem seus negócios em um cenário que estava constantemente mudando, como acontece com 0 sistema capitalista industrializado. "Se o mercado é uma mão invisível, o fracasso é como essa mão disciplina e rejeita os que não se enquadram no sistema. ${ }^{10 "}$ (SANDAGE, 2005, p.5). O sistema capitalista tem seus altos e baixos. Alguns serão catapultados enquanto outros conseguirão se adaptar. Na era do self-made man, o fracasso nos negócios era visto como uma tragédia moral incomensurável, como é representado na passagem seguinte de Sandage:

9 Franklinesque proverbs blamed failure on laziness, drunkenness, greed, ignorance, extravagance, and a host of other sins. But what to do when the market ejected -an honest, upright industrious \& economical manll? If the problem of failure was the fall of good men, its root was a growing breach between character and fortune, between rectitude and reward. The vicissitudes of capitalism were such that honest dealings and hard work could earn failure.

10 If the market is an invisible hand, failure is how that hand discipline and ejects the misfits of capitalism.

Revista de Letras JUÇARA, Caxias - Maranhão, v. 01, n. 01, p. 05 - 23, Jul. 2017. 
Em uma nação que está implementando o individualismo como seu credo, o loser era, ao mesmo tempo, intolerável e indispensável. O fracasso era a pior coisa que poderia acontecer a um americano que trabalhava duro e se dedicava, embora fosse a melhor prova que legitimava a empreeitada republicana de seus fundadores que haviam trocado o destino pelo mérito. Passar de trabalhador para empreendedor era o caminho para a virilidade e masculinidade ${ }^{11}$ (2005, p. 27).

A história dos primeiros perdedores se inicia com homens brancos de negócio no século XIX. Suas perdas financeiras e também suas perdas em relação à visão da masculinidade (já que um homem que fracassava não poderia ser visto como um homem de "verdade") levaram a cultura redefinir o fracasso: do dinheiro perdido em um caso de falência a oportunidades perdidas em uma vida desperdiçada. Essa mudança semântica coloca todo mundo em alerta. Pois, a partir de agora, todo mundo pode se tornar um ninguém. Embora o século XIX tenha sido um período de progresso e de prosperidade imperialista, o sistema capitalista apresentou um grande número de oscilações. O século é marcado por muitos momentos de variações financeiras. Em 1819 o mercado financeiro presenteou os americanos com um dos primeiros pânicos financeiros, quando uma poderosa depressão arruinou muitos e deixou o resto inquieto. (SANDAGE, 2005) Em muitos outros momentos do século, os americanos tiveram de se deparar a crises no setor econômico. O povo entendeu que o futuro poderia parecer arriscado e que, tanto o sucesso quanto o fracasso, poderiam estar batendo à porta.

\section{O século xx e os losers}

No início do século $\mathrm{XX}$, embora muitos americanos vivessem em áreas rurais, havia um enorme número de tecnologias aparecendo e assumindo relevância no estilo de vida norte americano. Milhares de estradas cruzavam o país; as rodovias na América eram mais extensas do que todas as rodovias da

${ }^{11}$ To a nation on the verge of anointing individualism as its creed, the loser was simultaneously intolerable and indispensable. Failure was the worst thing that could happen to a striving American, yet it was the best proof that the republican founders had replaced destiny with merit. Rising from laborer to entrepreneur was the path to manhood.

Revista de Letras JUÇARA, Caxias - Maranhão, v. 01, n. 01, p. 05 - 23, Jul. 2017. 
Europa juntas. Além disso, após a Segunda Guerra Mundial, os Estados Unidos se tornaram a economia mais poderosa e influente do globo. Americanos que viviam vidas fixas começaram a experimentar vidas mais móveis, em cidades ou em subúrbios das grandes áreas metropolitanas.

Nos anos que seguiram a segunda guerra mundial, a economia dos Estados Unidos, focada na manufaturação, tornou-se uma economia voltada para serviços e tecnologias de informação, características estas que marcam um país desenvolvido em nossa sociedade contemporânea. Hoje os americanos vivem "[...] no centro de uma rede de comunicações mundial ligada por aviões e satélites... uma era de ruídos poliglotas e da hipercomunicação ${ }^{12 " ~(R U L A N D ; ~}$ BRADBURY, 1991, p. 369). Depois da guerra muitos trabalhadores de colarinho azul perderam seus empregos e foram direcionados a posições diferentes e inferiores de trabalho. Para a América, era a época da dissolução da burguesia e a ascensão da cultura de massa. O sonho americano também estava mudando; empresas e o Governo estimulavam o consumismo, e a nação venerava o crescimento vertiginoso das metrópoles e dos subúrbios, que se tornou o lar para grande parte da classe média americana.

A revolução das tecnologias de informação moldaram a economia Americana e mundial em ritmo acelerado. Mais do que isso, moldaram a ideologia americana e o conceito de consumismo. A influência desta revolução pode ser exemplificada na seguinte citação:

\begin{abstract}
O que se seguiu depois da guerra foi uma época de materialismo, expansão militar, ansiedades ideológicas e um sentimento de rápida transformação de percepção. Esta foi a era da mídia, do registro instantâneo, do novo sistema de mensagens, da multiplicidade de estilos, da aceleração e confusão dos níveis de realidade ${ }^{13}$ (RULAND; BRADBURY, 1991, p. 371).
\end{abstract}

A ideologia que pregava um amanhã melhor tornou-se opaca. A crença que ditava que o trabalho duro, determinação e ambição poderia levar qualquer um ao

\footnotetext{
12 At the center of a network of world communications linked by plane and satellites technology, microchip messaging, interactive video or fax, an age of polyglot noise and hypercommunication.

${ }^{13}$ What followed the war was an age of materialism, military expansion, ideological anxiety and a sense of rapid transformation of consciousness. This was an age of the media, the instant record, the new message system, the multiplication of styles, the accelerating confusion of levels of reality.
}

Revista de Letras JUÇARA, Caxias - Maranhão, v. 01, n. 01, p. 05 - 23, Jul. 2017. 
sucesso, foi despedaçada. Ao invés disso, hoje, encontramos os americanos à deriva em um oceano sem ondas, distanciando-se dos princípios que fundaram a nação. Eles têm muitas suspeitas sobre o presente e são muito inseguros em relação ao futuro. De acordo com Bernard Carl Rosen, a transformação ideológica de muitos americanos advém da mudança na estrutura econômica que se seguiu nas últimas três décadas do século $X X$, quando os meios de produção, que dependiam da força manufatureira, foram deslocados para posições inferiores por uma nova economia baseada nas tecnologias e serviços. Esta nova economia é impiedosa com aqueles que não conseguem se adaptar a ela. Bíceps saudáveis perderam prestígio e utilidade no local de trabalho. Muitos americanos que viviam vidas "saudáveis, honestas e valorosas" como trabalhadores na indústria manufatureira foram substituídos por estratégias de mercado que pudessem se moldar às condições cambiantes do mercado. A classe trabalhadora, até os anos 70, tinha adquirido muitos direitos. Seus salários eram "justos", eles tinham empregos estáveis, seguro, e tinham direito a uma boa aposentadoria, em outras palavras, eles haviam se tornado caros demais (ROSEN, 1998).

De acordo com os dogmas do novo mercado, os países desenvolvidos transferiram suas fábricas para países subdesenvolvidos, onde os trabalhadores são baratos, há poucos direitos trabalhistas, a legislação é deficiente e as pessoas trabalham por muitas horas. Com essas mudanças na estrutura econômica da América, não há grupo que se sinta mais mal tratado do que a classe trabalhadora. A classe trabalhadora é menosprezada pela sociedade americana e pelo mercado. Eles foram pegos de surpresa em uma revolução mercantil que não pertence a eles, mas da qual não podem escapar.

\section{O loser como um descentrado}

Um grande número de teóricos e artistas da pós-modernidade questionam os conceitos humanistas liberais. Quando falamos de Humanismo Liberal, nós estamos falando de seu ímpeto centralizador e totalizante, de seus conceitos de autonomia, transcendência, certeza, autoridade, unidade, totalidade, sistema, 
universalidade, centro, continuidade, hierarquia, homogeneidade, exclusividade e origem.

Linda Hutcheon elucida que questionar o Humanismo Liberal não é negálo, mas questionar sua relação com a experiência. O pós-modernismo é um "[...] fenômeno contraditório, um que usa e abusa, instala e subverte, o próprio conceito que se opõe ${ }^{14 "}(1988$, p. 3). Hutcheon ressalta que o pós-modernismo é o resultado de uma postura interrogativa, além de ser uma oposição à autoridade que advém do cenário político dos anos 60 . Um dos grandes questionamentos, dos teóricos pós-modernos, recai sobre o conceito de centro. O que é o centro? Desde quando o "centro" é o centro? Nós vivemos em uma época em que estamos repansando a questão do centro, e, a partir disso, refletindo sobre as margens e as fronteiras. Estamos nos desviando dos conceitos de unidade e origem.

Quando o centro cede espaço para às margens, as contradições que existem nas convenções se tornam discerníveis, e é nesse momento que o jogo da linguagem assume sua posição. Quando tudo que simbolizava centro e origem é desconstruído, aparece o espaço para o deslocameto. E, embora o "centro" possa não prevalecer, ele ainda é um subterfúgio atrativo para as artes enquanto representação de uma ficção que pode ser compreendida como sistema de ordem e unidade.

Os contos de Raymond Carver podem ser conectados a esta característica, já que seus personagens vêm de lugares isolados do noroeste dos Estados Unidos, normalmente nos estados de Oregon, Washington ou Alaska, ou como o título de um de seus livros sugere: Sem Heroísmo, Por Favor (1991) As cidades pequenas são descritas quase como um reflexo de seus personagens, que, de acordo com Michael Gearhart "[...]são personagens perdidos de colarinho azul, familiarizados com o trauma da infidelidade matrimonial alcoolismo e dificuldades financeiras ${ }^{15} . "(1984$, p.439).

O indivíduo descentrado é inevitavelmente identificado com o centro que ele aspira, mas do qual ele é negado. Nos trabalhos de Raymond Carver, o leitor

${ }^{14}$ Contradictory phenomenon, one that uses and abuses, installs and then subverts, the very concepts it challenges.

${ }^{15}$ Are a down-and-out blue-collar type familiar with the trauma of marital infidelity, alcoholism and financial hardship.

Revista de Letras JUÇARA, Caxias - Maranhão, v. 01, n. 01, p. 05 - 23, Jul. 2017. 
tem muita influência sobre o texto. O estilo elíptico de Carver permite aos leitores ter uma participação ativa no ato de construir a história. O leitor preenche as lacunas da narrativa, inferindo sentido nos momentos de silêncio e ambiguidade. Esta atitude perante o leitor é um dos aspectos mais marcantes na literatura pósmoderna.

O final aberto é outra característica do pós-modernismo. Dependerá do conhecimento do mundo e dos discursos que o constituiram, além, de sua posição, como sujeito, que o leitor poderá extrair o máximo destas histórias. A ideia da perspectiva é recorrente na arte pós-moderna, porque pode representar a possibilidade de realidades diferentes, além de ressaltar a diferença de classes e experiencias.

A possibilidade de ouvir múltiplas vozes faz com que conheçamos histórias que foram silenciadas ou, que sempre foram contadas através de uma perspectiva phalocêntrica. Escritores negros e de descendência indígena não apenas expõe uma perspectiva étnica a respeito da realidade em um mundo dominado pela voz branca, mas também recontam a história pelos olhos do explorado e não do explorador. Este grupo de artistas estava interesado em recontar a história pela perspectiva do Outro. Os escritores pós-modernos representam as minorias, como os Afro-americanos, nativos-americanos, homosexuais, mulheres, imigrantes, entre outros.

Quando Raymond Carver lançou seu primeiro livro de contos Will you please be quiet, please? (1976) os seus personagens eram representantes de uma classe social agonizando em dívidas, desempregadas, pessoas que tiveram seus casamentos arruinados por problemas financeiros, infidelidade e falta de comunicação; pessoas que desejavam ter vidas diferentes. Carver e seus personagens representam os descentrados pela classe e pela geografia, já que a maioria de seus personagens, incluindo o próprio autor, viviam em cidades remotas, às margens do mundo moderno, normalmente nos estados de Oregon, Washington e Alaska. Os personagens que habitam as narrativas de Carver não são negros, gays ou imigrantes. De fato, as mulheres retratadas em suas histórias vivem em um mundo regido pelas "leis" do mundo masculino. E mesmo assim, os personagens de Carver são losers brancos e machos, perdidos em um mundo que os rejeita. Os personagens são completamente excluídos de qualquer 
posição de poder na sociedade. Normalmente são alcoolatras desempregados que sentem que o mundo é um lugar perigoso e suspeito. A sensação de inadequação dos personagens reverbera em suas inabilidades comunicativas em relação ao Outro. Os personagens são sufocados e solitários.

\section{Os losers de Raymond Carver}

Em Raymond Carver as formações ideológicas são lineares e restritas. Permitir que os personagens se desloquem para outras formações ideológicas sempre representa um grande risco e uma possibilidade de colapso. Os personagens estão aprisionados a uma identidade fixa, que os condena a posições subalternas em relação ao mundo e ao Outro, qualquer Outro. Embora estejamos vivendo em um mundo heterogêneo, nos contos de Carver a realidade é colocada com tendências homogêneas. Esta característica deve ser levada em conta pelo analista, porque, revela um aspecto interesante no trabalho do escritor, que é a materialidade ideológica e como ela é retratada nas histórias.

Raymond Carver criou um universo aonde as personagens se sentem sufocados e ameaçados pelo mundo exterior. E, é no discurso (a exterioridade), tanto nas palavras como nos momentos de silêncio, que o leitor/analista percebe a grande tensão e o potencial para o calapso existente no mundo das personagens. O estilo de escrita de Carver cria uma tensão no texto porque há enormes silêncios em suas personagens, que Susan Sontag classifica como "a estética do silêncio". Ele explica que "[...] o silêncio permanece, inescapavelmente, uma forma de discurso (em muitas instâncias como uma acusação) e um elemento de diálogo ${ }^{16 " . ~(1982, ~ p .181) ~ T u d o ~ n a ~ v i d a ~ d o s ~}$ personagens é um fator de ameaça, como podemos perceber na passagem seguinte:

Eu gosto quando há uma sensação de ameaça ou perigo nas histórias. Eu acredito que um pouco de ameaça é bom de se ter em uma história. Por uma razão, é bom pra circulação. Tem que haver tensão, uma sensação de que algo é iminente, que algumas coisas estão em inexorável movimento, ou, de outra forma, simplesmente não haveria nenhuma história. $O$ que cria a tensão em uma peça de ficção é

${ }^{16}$ Silence remains inescapably, a form of speech (in many instances, of complaint or indictment) and an element in a dialogue.

Revista de Letras JUÇARA, Caxias - Maranhão, v. 01, n. 01, p. 05 - 23, Jul. 2017. 
parcialmente a forma concretaem que as palavras estão ligadas para dar a ação na história. Mas também, são as coisas que são deixadas de fora, que estão implícitas, a paisagem escondida (mas às vezes quebradas e inquietas) sob a superfície das coisas $^{17}$ (CARVER, 1983, p.26).

Os contos de Carver são habitados por sujeitos completamente separados um do outro, alienados e temerosos em se comunicar, embora a comunicação seja um desejo latente entre eles. Cada tentativa de aproximação entre as personagens, na estrutura discursiva, cria uma possibilidade de catástrofe, ou, a possibilidade do equivoco e deslocamento. Transitar entre diferentes formações ideológicas seria violar a norma, violar a estabilidade. Miriam Marty Clark escreveu em seu ensaio Depois da epifania: contos americanos na era pós-moderna, que:

\begin{abstract}
Há histórias que se movem, como as histórias de Raymond Carver fazem, com uma força centrípeta, colapsando em uma estrutura linguística mínima, determinando também como é linguisticamente isolada. Aqui, o silêncio não tem a ver com o indescritível, mas com a própria linguagem: a conversa interompida, a palavra insuficiente, a incomensurabilidade das linguages dentro de um casamento [...] Os personagens de Carver são incapazes de sustentar uma multivocalidade, a heteroglossia da palavra e, não coincidentemente, do discurso novelistico como Bakhtin define. As narrativas de Carver, dessa forma, estão condenadas a serem histórias curtas. A fonte da narrativa, e do próprio ser, são sufocadas pelo medo e a impossibilidade da comunicação ${ }^{18}$ (1993, p.390).
\end{abstract}

Em um mundo frágil e opressor, as personagens de Carver vivem sob a sombra de uma ideologia dominante. Os sujeitos só alcançam e tocam o Outro através do silêncio. A comunicação é estabelecida pelo silêncio. As fronteiras

\footnotetext{
17 I like it when there is some feeling of threat or sense of menace in sort stories. I think a little menace is fine to have in a story. For one thing, it is good for the circulation. There has to be tension, a sense that something is imminent, that certain things are in relentless motion, or else, more often, there simply won't be a story. What creates tension in a piece of fiction is partly the way the concrete words are linked together to make up the visible action of the story. But it is also the things that are left out, that are implied, the landscape just under the smooth (but sometimes broken and unsettled) surface of things.

18 There are stories that move, as Raymond Carver's do, with centripetal force, collapsing into a minimal selfhood linguistically determined even as it is linguistically isolated. Here silence has to do not with the ineffable but with language itself: the broken conversation, the insufficient word, the incommensurability of languages even within marriage [...] Carver's characters are unable to sustain the multivocality, the heteroglossia of the word and, not coincidentally, of novelistic discourse as Bakhtin defines it. Carver's narratives seem, on that account, bound to be short stories. The very source of narrative, and hence of the self, are choked off by the fear, the impossibility of communication.
}

Revista de Letras JUÇARA, Caxias - Maranhão, v. 01, n. 01, p. 05 - 23, Jul. 2017. 
desta formação ideológica assujeitada a uma ideologia do oprimido só trespassa seus limites pelo silêncio. Tudo que vem das palavras gera medo e suspense. $\mathrm{O}$ telefone ou uma campainha tocando são sintomas de ameaça. Um bom exemplo pode ser mostrado no primeiro parágrafo de Ponha-se no Meu Lugar, um conto que aparece em sua primeira coleção de contos:

\begin{abstract}
O telefone tocou na hora em que ele estava passando aspirador de pó. Tinha feito a faxina em uma parte do apartamento e agora estava na sala, usando o bico fino para tirar os pelos do gato entranhados nas almofadas. Parou, escutou e depois desligou o aspirador. Foi atender 0 telefone (CARVER, 2010, p.171).
\end{abstract}

O leitor de Carver, da mesma forma, quando se depara com os espaços em branco entre cada enunciado, entre cada vírgula ou ponto, preenche estes espaços com tensão e ansiedade, sem entender totalmente o que está ou pode estar acontecendo.

As personagens de Raymond Carver parecem ser extremamente frágeis, incapazes de resolver problemas relacionados a dinheiro ou casamento. Seus protagonistas e personagens secundários não diferem no que concerne à ausência de confiança ou falta de habilidade e inarticulação em relação à fala.

O universo criado por Carver é completamente pessimista, já que suass personagens não tem nenhuma ambição e, de certa forma, não estão preparados para aceitar os papéis que a sociedade reservou a eles. Eles não estão preparados para serem pais, maridos e esposas, ou até mesmo empregados. Estas personagens e o mundo que elas representam estão prestes a entrar em colapso, como um de seus personagens em seu segundo livro - Do Que Estamos Falando Quando Estamos Falando De Amor - percebe: "Ele compreendeu que bastava um lunático com uma tocha pra levar tudo à ruína ${ }^{19 "}$ (CARVER, 1981, p.76). Outro personagem em seu primeiro livro - Você Poderia Ficar Quieta, Por Favor? - tamém comenta que "[...] sim, havia um grande mal levando o mundo, ele pensou, e ele apenas precisava de um pequeno empurrão, de uma brecha. ${ }^{20 "}$ (CARVER, 1976, p.241).

\footnotetext{
${ }^{19} \mathrm{He}$ understood that it took only one lunatic with a torch to bring everything to ruin.

${ }^{20}$ Yes, there was a great evil pushing at the world, he thought, and it only needed a slipway, a little opening.
}

Revista de Letras JUÇARA, Caxias - Maranhão, v. 01, n. 01, p. 05 - 23, Jul. 2017. 
A respeito do pessimismo que Carver aplicava em seus contos, podemos fazer referência ao que Clark escreveu quando descrevia as tendências nos contos do pós-modernismo: "distanciar-se do conhecido em direção a desilisão mais do que a revelação e reintegração ${ }^{21 ”}$. (1993, p.388) Quando perguntaram a Carver se suas personagens estavam tentando fazer a diferença, ele respondeu:

\begin{abstract}
Eu acho que eles estão tentando. Mas tentar e ser bem-sucedido são coisas completamente diferentes. Em algumas vidas, as pessoas sempre são bem-sucedidas [...] em outras vidas, as pessoas não conceguem fazer o que tentam fazer [...] Estas vidas são, evidentemente, válidas para se escrever sobre, a vida das pessoas que não têm sucesso. A maioria das minhas experiências próprias tem a ver com essa condição [...] É com a própria vida que eles ficaram desconfortáveis, vidas que eles vêm se despedaçando. Eles gostariam de consertar as coisas, mas eles não conseguem. E, normalmente, eles sabem disso, eu acho, e sabendo disso, eles fazem o melhor que eles podem. ${ }^{22}$ (1983, p. 201).
\end{abstract}

\title{
Considerações finais
}

Raymond Carver "deu voz", pelo silêncio a este loser. Esta personagem fascinante que nasce da cultura norte-americana e da necessidade de sucesso, e que permeia toda a história e cultura moderna americana. Nos contos do escritor, as personagens representam a classe trabalhadora, e se deparam com um futuro sem perspectivas de ascensão social. Eles são maridos e esposas em constante dificuldade financeira: estão constantemente mudando de empregos, ou desempregados, ou até mesmo, trabalhando em dois empregos para pagar as contas. Carver dá voz ao homem comum, o zelador, a garçonete, o padeiro, o recepcionista de hotel. Como a maioria dos americanos, as personagens de Carver vivem vidas de desespero silencioso, de alienação e insatisfação. Inconscientes do que eles realmente sentem, a maioria vive sob a submição ideológica de uma cultura dominante. As personagens do universo de Carver não possuem ambição, eles estão fora da corrida. Elas estão tão assoberbadas com

\footnotetext{
${ }^{21}$ Move away from the known toward disillusionment rather than revelation and reintegration.

22 I think they are trying. But trying and succeeding are two different matters. In some lives, people always succeed [...] In other lives, people don't succeed at what they are trying to do [...] These lives are, of course, valid to write about, the lives of the people who don't succeed. Most of my own experience has to do with the latter situation [...] It's their lives they've become uncomfortable with, lives they see breaking down. They'd like to set things right, but they can't. And usually they do know it, I think, and after that they just do the best they can
}

Revista de Letras JUÇARA, Caxias - Maranhão, v. 01, n. 01, p. 05 - 23, Jul. 2017. 
os seus problemas que não há espaço para a ambição. As personagens são sobreviventes tentando manter uma certa ordem em suas vidas turbulentas. $O$ desafio para eles não é a ascensão social ou financeira, mas sim, a sobrevivência social e financeira. As dificuldades em viver em um lar despedaçado, aonde a desintregação familiar, o alcoolismo, a infidelidade e a falência estão sempre batendo à porta. Estes são os elementos que fermentam as histórias. A falta de ambição das personagens podem ser analisadas na maioria de seus contos. Em um de seus livros mais prestigiados - Do Que Estamos Falando Quando Estamos Falando De Amor (2010) - as personagens se deparam regularmente com estas situações. No conto Coreto, podemos entender o quanto os sonhos das persongens são pequenos e se distanciam dos ideais americanos de aquisição e sucesso. No conto, um casal é responsável por cuidar de um pequeno hotel. $\mathrm{O}$ emprego parece perfeito, e inicialmente eles vêm a si mesmos como pessoas privilegiadas. "Logo que a gente se mudou para cá e começou a trabalhar na gerência do hotel, achávamos que estávamos a salvo. Moradia e utensílios de graça, mais trezentos por mês. Não dá pra recusar” (2010, p. 284).

Os descentrados de Carver não são apenas marginalizados socialmente e financeiramente. Geograficamente, eles também estão fora do centro. A maior parte das histórias de Carver se passa em pequenas cidades do Alaska, ou em Yakima e Port Angels, cidades pequenas no estado de Washington, ou, até mesmo em El Paso, Califórnia. A viúva de Carver, Tess Gallagher comenta que tanto as personagens como os lugares são muito parecidos, e como eles se complementam. "A propensão de Ray em colocar uns truques em sua escrita, favorecendo a simplicidade a ornamentação, preferindo a economia como elemento para o verossímil - estes parecem ser elementos presentes na paisagem de Yakima23" (1990, p. 9).

Esta posição/sujeito loser, nascida na cultura capitalista norte-americana, esta esculpida nas personagens criadas por Carver. As relações humanas nas histórias do escritor estão repletas de ansiedade e fúria. Não é por acaso que muitas de suas histórias terminam com algum tipo de violência. Os losers de

\footnotetext{
${ }^{23}$ Ray's proclivity for scorning tricks in his writing, for favoring simplicity over ornamentation, for choosing economy as the most telling sign of veracity - these seem present in elements of the Yakima landscape.
}

Revista de Letras JUÇARA, Caxias - Maranhão, v. 01, n. 01, p. 05 - 23, Jul. 2017. 
Raymond Carver são sobreviventes e eles resistem em um mundo que os coibe e os marginaliza.

\title{
RAYMOND CARVER AND HIS LOSERS:
}

\section{A BRIEF HISTORY OF THE LOSER IN AMERICA}

\begin{abstract}
This paper has the objective to trace the history of the Losers in modern and postmodern North America, scrutinizing the power of the imaginary about the foundation of the nation as a fundamental element to the birth and raise of these losers. Moreover, the construction of the Losers is analyzed in the literature of Raymond Carver, where most of his characters can be identified as this ex-centric group in the American nation. An interdisciplinary approach between history and literature is required to deal with the reading of the American imaginary, surrounding ideals of success, and how they open space to the raise of a loser ideology. So that history can be scrutinized, concepts of Micro-History and New History are brought to the discussion. Additionally, the characters in Raymond Carver stories are analyzed through the concept of Linda Hutcheon and the ex-centrics of post-modernity.
\end{abstract}

Keywords: Raymond Carver. Losers. Hiistory. New Histoty. America.

\section{Referências}

ADELMAN, Bob. Carver country: The world of Raymond Carver. New York: Macmillan, 1990.

BURKE, Peter (org.) A Escrita da História: novas perspectivas. São Paulo: UNESP, 2011.

CARVER, Raymond. 68 contos de Raymond Carver. São Paulo; Companhia das Letras, 2010.

. Call If You need me. New York: Vintage Books, 2001. . No heroics, please. New York: Vintage Books, 1992. . Fires. New York: Vintage Books, 1983.

. What we talk about when we talk about love. New York: Vintage

Books, 1981.

. Will you please be quiet, please? New York: Vintage Books, 1976.

HUTCHEON, Linda. The politics of postmodernism. London: Routledge, 1989.

JENKINS, Keith. A história repensada. São Paulo: Contexto, 2001.

LYOTARD, Jean-François. The postmodern condition: a report on knowledge

Revista de Letras JUÇARA, Caxias - Maranhão, v. 01, n. 01, p. 05 - 23, Jul. 2017. 
Minneapolis: Minnesota Press, 1984.

ROSEN, Bernard Carl. Winners and losers of the Information Revolution. Westport, Connecticut: Praeger, 1998.

SAHLINS, Marshall David. Ilhas da História. Rio de Janeiro: Zahar, 2011.

SANDAGE, Scott A. Born losers: a history of failure in America. Boston: Harvard University Press, 2005.

VAINFAS, Ronaldo; CARDOSO, Ciro Flamarion (orgs.) Domínios da História: ensaios da teoria e metodologia. Rio de Janeiro: Elsevier, 2011.

WHITE, Hayden. Meta-história: a imaginação histórica do século XIX. São Paulo: Edusp, 1995.

Data de Submissão: 27/12/16

Data de Aprovação: 06/05/17 